\title{
Exploring the Therapeutic Effects of Bhastrika Pranayama on Hematological Parameters: An Ancient Practice with Modern Relevance
}

\author{
Baljinder Singh Bal \\ Department of Physical Education, Guru Nanak Dev University, Amritsar Punjab, India
}

Email address:

bal_baljindersingh@yahoo.co.in

To cite this article:

Baljinder Singh Bal. Exploring the Therapeutic Effects of Bhastrika Pranayama on Hematological Parameters: An Ancient Practice with Modern Relevance. International Journal of Language and Linguistics. Vol. 3, No. 3, 2015, pp. 116-121. doi: 10.11648/j.ij11.20150303.12

\begin{abstract}
The purpose of this study was to investigate the effects of bhastrika pranayama on hematological parameters. Thirty Two, university level girls of Department of Physical Education (T), Guru Nanak Dev University, Amritsar between the age group of 19-25 years (Mean \pm SD: age $21.718 \pm 1.887$ years, height $5.581 \pm 2.235$ feet's, body mass $68.612 \pm 4.209 \mathrm{~kg}$ ) volunteered to participate in the study. The subjects from Group-A: Experimental were subjected to a 4-week bhastrika pranayama. Student $t$ test for paired samples was utilized to compare the means of the pre-test and the post-test. No significant differences were found in Hemoglobin (Hb), Total Cholesterol (TC), Low Density Lipoprotein Cholesterol (LDL-Cholesterol), High Density Lipoprotein Cholesterol (HDL-Cholesterol) and Triglycerides (TG) among University Level Girls.
\end{abstract}

Keywords: Bhastrika Pranayama, Hemoglobin, Total Cholesterol, Low Density Lipoprotein Cholesterol, High Density Lipoprotein Cholesterol, Triglycerides

\section{Introduction}

The ancient research in relation to attaining purification of human body, mind, and soul is commonly brought under the umbrella term of "Pranayama". Speaking etymologically, "Pranayama" is a Sanskrit word comes from the roots prana (universal energy), and yama (to control). Thus, Pranayama is used to control, cultivate, and modify the Prana in the body. Its essence lies in the modification of our normal process of breathing. Pranayama entails of modifications of the breathing process which we bring about deliberately and consciously. The beneficial effects of different pranayama are well reported and has sound scientific basis $(1,2)$. The effect of different pranayamas on healthy (3) and diseased people (4, $5,6)$ has been well studied and they are known to affect the cardiopulmonary activities and autonomic functions. Growing number of evidences have claimed that yoga practices increases longevity, (7) has therapeutic (8) and rehabilitative effects (9). There are various techniques of pranayama but we have applied the technique of Bhastrika
Pranayama on the subjects.

\section{Material and Methods}

\subsection{Subjects}

Thirty Two, university level girls of Department of Physical Education (T), Guru Nanak Dev University, Amritsar between the age group of 19-25 years (Mean \pm SD: age $21.718 \pm 1.887$ years, height $5.581 \pm 2.235$ feet's, body mass $68.612 \pm 4.209 \mathrm{~kg}$ ) volunteered to participate in the study. The subjects were purposively assigned into two groups:

- Group-A: Experimental (n1=16)

- Group-B: Control (n2=16)

All the subjects were informed about the objective and protocol of the study. Distribution and demographics of subjects are presented in (Table-1). 
Table 1. Distribution and Demographics of Subjects.

\begin{tabular}{llll}
\hline Sample Size $(\mathbf{N}=\mathbf{3 2})$ & & & \\
\hline Variables & Total $(\mathbf{N}=\mathbf{3 2})$ & Experimental group $(\mathbf{n 1}=\mathbf{1 6})$ & Control group $(\mathbf{n 2 = 1 6 )}$ \\
\hline Age & $21.718 \pm 1.887$ & $21.375 \pm 1.962$ & $22.062 \pm 1.806$ \\
Body Height & $5.581 \pm 2.235$ & $5.631 \pm 2.386$ & $5.531 \pm 2.023$ \\
Body Mass & $68.612 \pm 4.209$ & $69.131 \pm 3.673$ & $68.093 \pm 4.750$ \\
\hline
\end{tabular}

\subsection{Methodology}

This study is designed as a retrospective cross-sectional study. The subjects from Group-A: Experimental were subjected to a 4-week Bhastrika Pranayama. This lasted 4 weeks and consisted of daily sessions. Hemoglobin was determined in the blood samples of all the subjects with the use of a hematology analyzer (Celldyne model 3500). Blood samples $(10 \mathrm{ml})$ for the determination of lipid profiles were obtained. All of biochemical tests have been done with serum samples. Lipid parameters (Triglyceride; Cholesterol; Lowdensity lipoprotein; High-density lipoprotein) were measured using Boehringer Mannheim kits and Clinilab, BioMerieux analyser as used by Jastrzebska et al. (10).

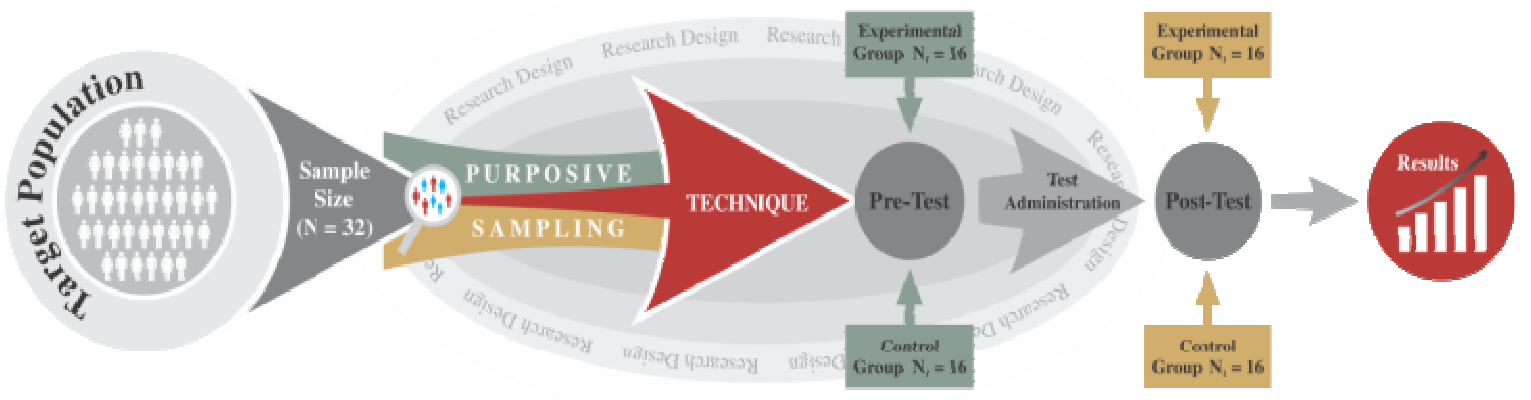

Figure 1. Study Design.

Table 2. Experimental Treatment

\begin{tabular}{llll}
\hline 4-Weeks Bhastrika Pranayama Training & Time & Duration \\
\hline Weeks & Schedule & 5 Minute \\
\hline \multirow{2}{*}{$1^{\text {st }}$ Week } & Preliminary Yogic Exercises & 10 Minute & 20 Minute \\
& Practice of Anuloma Viloma Pranayama (9 Rounds X 1 Set) & 5 Minute \\
& Relaxation Posture & 5 Minute \\
\multirow{2}{*}{$2^{\text {nd }}$ Week } & Preliminary Yogic Exercises & 15 Minute \\
& Practice of Anuloma Viloma Pranayama (9 Rounds X 2 Set) & 5 Minute & 25 Minute \\
& Relaxation Posture & 5 Minute \\
\multirow{2}{*}{$3^{\text {rd }}$ Week } & Preliminary Yogic Exercises & 20 Minute \\
& Practice of Anuloma Viloma Pranayama (9 Rounds X 3 Set) & 5 Minute & 30 Minute \\
& Relaxation Posture & 5 Minute \\
$4^{\text {th }}$ Week & Preliminary Yogic Exercises & 25 Minute & 35 Minute \\
& Practice of Anuloma Viloma Pranayama (9 Rounds X 4 Set) & 5 Minute \\
\hline
\end{tabular}
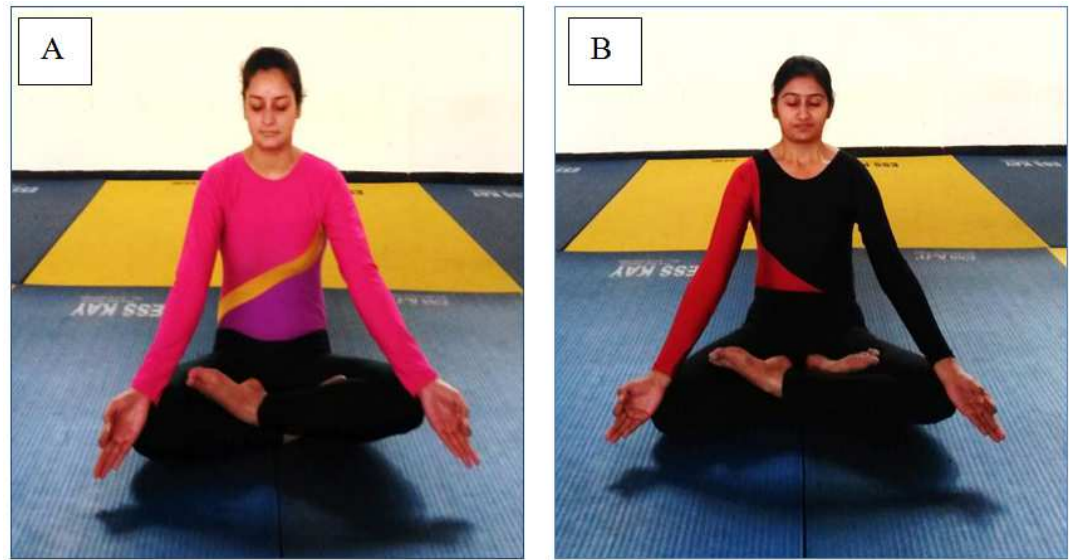

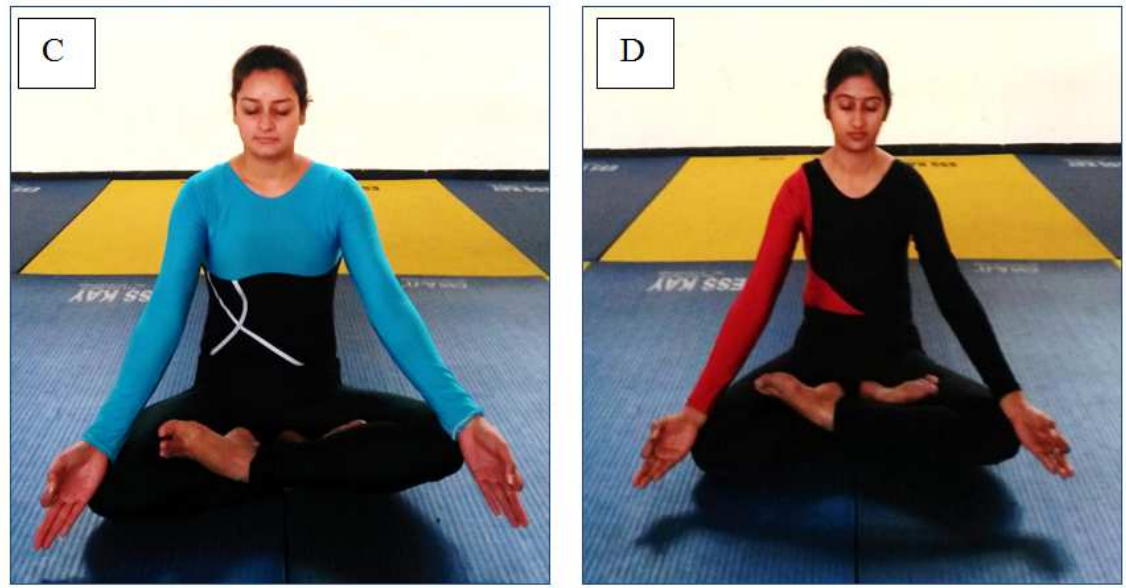

Figure 2. Subject Performing Bhastrika Pranayama
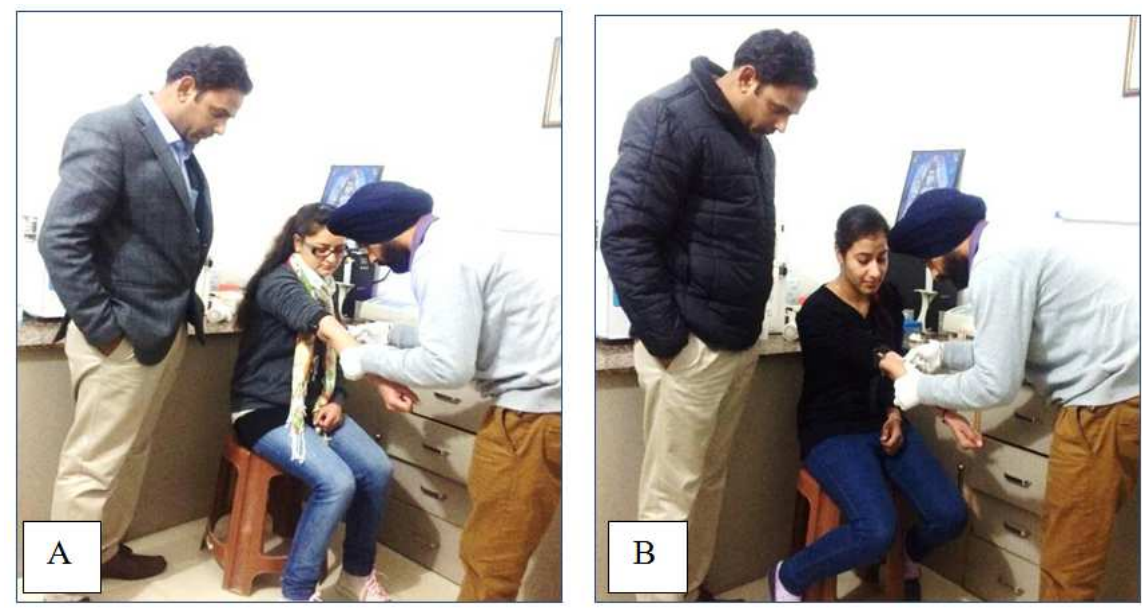

Figure 3. Biochemical tests with serum samples.

\section{Statistical Analysis}

Statistical analyses were performed using the Statistical Package for the Social Sciences for Windows version 10.0 software (SPSS Inc., Chicago, IL). Data is expressed as the mean \pm SD. Student $t$ test for paired samples was utilized to compare the means of the pre-test and the post-test. To test the hypothesis, the level of significance was set at 0.05 .

\section{Results}

The results of Hematological Parameter (i.e., Hemoglobin (Hb), Total Cholesterol (TC), Low Density Lipoprotein Cholesterol (LDL-Cholesterol), High Density Lipoprotein Cholesterol (HDL-Cholesterol) and Triglycerides (TG) in university level girls are presented in (Table-3):

Table 3. Descriptive Statistics (Mean \& Standard Deviation) and Paired Sample t-test of Hematological Parameter (i.e., Hemoglobin (Hb), Total Cholesterol (TC), Low Density Lipoprotein Cholesterol (LDL-Cholesterol), High Density Lipoprotein Cholesterol (HDL-Cholesterol) and Triglycerides (TG) of University Level Girls.

\begin{tabular}{|c|c|c|c|c|c|c|}
\hline \multicolumn{7}{|l|}{ Hemoglobin (Hb) } \\
\hline Group & Number & Mean & Standard Deviation & Standard Error of the Mean & t-value & p-value \\
\hline Experiment (Pre-test) & 16 & 13.225 & 0.606 & 0.151 & \multirow{2}{*}{1.567} & \multirow{2}{*}{0.138} \\
\hline Experimental (Post-test) & 16 & 13.262 & 0.612 & 0.153 & & \\
\hline Control (Pre-test) & 16 & 13.043 & 0.654 & 1.321 & \multirow{2}{*}{1.321} & \multirow{2}{*}{0.206} \\
\hline Control (Post-test) & 16 & 13.075 & 0.610 & 0.206 & & \\
\hline \multicolumn{7}{|l|}{ Total Cholesterol (TC) } \\
\hline Experiment (Pre-test) & 16 & 154.981 & 10.414 & 2.603 & \multirow{2}{*}{1.000} & \multirow{2}{*}{0.333} \\
\hline Experimental (Post-test) & 16 & 155.006 & 10.416 & 2.604 & & \\
\hline Control (Pre-test) & 16 & 155.862 & 11.555 & 2.888 & \multirow{2}{*}{0.488} & \multirow{2}{*}{0.632} \\
\hline Control (Post-test) & 16 & 155.875 & 11.577 & 2.894 & & \\
\hline \multicolumn{7}{|c|}{ Low Density Lipoprotein Cholesterol (LDL-Cholesterol) } \\
\hline Experiment (Pre-test) & 16 & 114.668 & 6.779 & 1.695 & 0.764 & 0.456 \\
\hline
\end{tabular}




\begin{tabular}{llllll}
\hline Hemoglobin (Hb) & \multicolumn{7}{l}{} & & \\
\hline Group & Number & Mean & Standard Deviation & Standard Error of the Mean & t-value \\
\hline Experimental (Post-test) & 16 & 114.687 & 6.769 & 1.692 & p-value \\
Control (Pre-test) & 16 & 113.081 & 6.266 & 1.566 & 0.222 \\
Control (Post-test) & 16 & 113.087 & 6.327 & 1.582 & 0.826 \\
High Density Lipoprotein & Cholesterol (HDL-Cholesterol) & & & \\
Experiment (Pre-test) & 16 & 67.850 & 3.559 & 0.889 & 0.939 \\
Experimental (Post-test) & 16 & 67.875 & 3.602 & 0.900 & 0.362 \\
Control (Pre-test) & 16 & 70.531 & 5.389 & 1.347 & 0.251 \\
Control (Post-test) & 16 & 70.537 & 5.392 & 1.342 & 0.805 \\
Triglycerides (TG) & & & & & \\
Experiment (Pre-test) & 16 & 135.331 & 7.651 & 1.912 & 2.070 \\
Experimental (Post-test) & 16 & 135.381 & 7.649 & 1.912 & 0.056 \\
Control (Pre-test) & 16 & 130.900 & 6.816 & 1.704 & 1.074 \\
Control (Post-test) & 16 & 130.925 & 6.852 & 1.713 & 0.299 \\
\hline
\end{tabular}

\begin{tabular}{|c|c|c|c|c|c|}
\hline \multirow[t]{2}{*}{$\begin{array}{r}2.5 \\
2 \\
1.5 \\
1 \\
0.5 \\
0\end{array}$} & 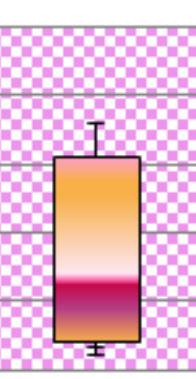 & 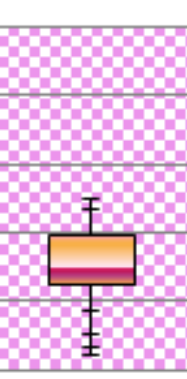 & 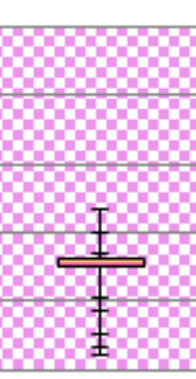 & 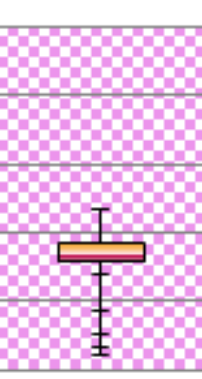 & $\mathrm{T}$ \\
\hline & $\begin{array}{c}\text { Hemoglobin } \\
(\mathrm{Hb})\end{array}$ & $\begin{array}{c}\text { Total } \\
\text { Cholesterol } \\
\text { (TC) }\end{array}$ & $\begin{array}{c}\text { Low Density } \\
\text { Lipoprotein } \\
\text { Cholesterol } \\
\text { (LDL- } \\
\text { Cholesterol) }\end{array}$ & $\begin{array}{c}\text { High Density } \\
\text { Lipoprotein } \\
\text { Cholesterol } \\
\text { (HDL- } \\
\text { Cholesterol) }\end{array}$ & $\begin{array}{c}\text { Triglycerides } \\
\text { (TG) }\end{array}$ \\
\hline Experiment $t$-value & 1.567 & 1 & 0.764 & 0.939 & 2.07 \\
\hline Control t-value & 1.321 & 0.488 & 0.222 & 0.251 & 1.074 \\
\hline Experiment p-value & 0.138 & 0.333 & 0.456 & 0.362 & 0.056 \\
\hline Control p-value & 0.206 & 0.632 & 0.826 & 0.805 & 0.299 \\
\hline
\end{tabular}

Figure 4. $t$-value and p-value for the Experimental (Pre-Test \& Post-Test) and Control (Pre-Test \& Post-Test) Groups Scores of Hematological Parameter.

\subsection{Hemoglobin (Hb)}

The results of Hematological Parameter in group (Experimental) and group (Control) are shown in (Table-3). The Mean and Standard Deviation values of Hemoglobin $(\mathrm{Hb})$ of pre-test and post-test of experimental group was $13.225 \pm$ 0.606 and $13.262 \pm 0.612$ respectively. However, the Mean and Standard Deviation values of Hemoglobin $(\mathrm{Hb})$ of pretest and post-test of control group were $13.043 \pm 0.654$ and $13.1075 \pm 0.610$. The $t$-value in case of experimental group was 1.567 and for control group it was 1.321 .

No significant between-group differences were noted in Hemoglobin $(\mathrm{Hb})$ since the calculated value of $(\mathrm{t}=1.567)$ is smaller than tabulated value of $t .05(15)=2.13$ for the selected degree of freedom and level of significance. The data does suggest that the differences between pre-test and post-test of Hemoglobin $(\mathrm{Hb})$ in experimental and control group are insignificant.
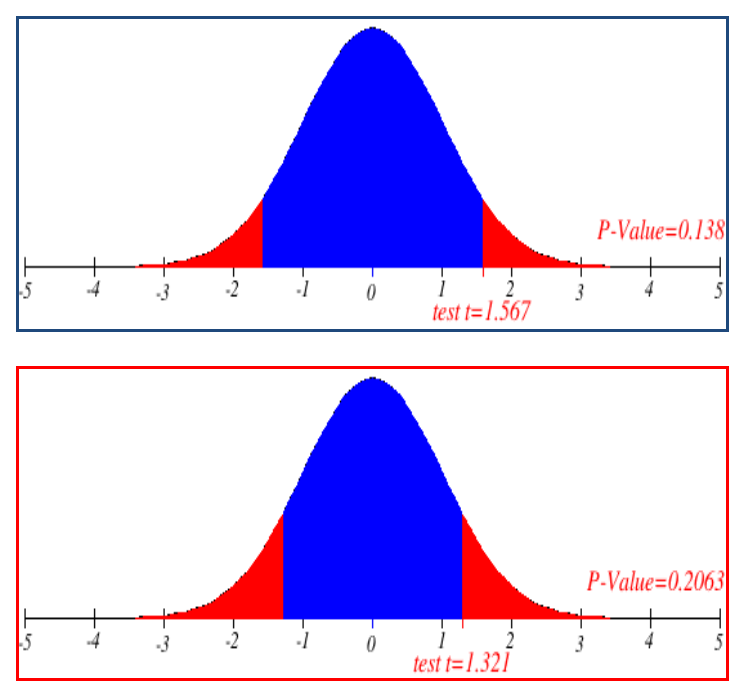

Figure 5. $t$-test and p-value for the Experimental (Pre-Test \& Post-Test) and Control (Pre-Test \& Post-Test) Groups on the parameter Hemoglobin (Hb). 


\subsection{Total Cholesterol (TC)}

The Mean and Standard Deviation values of Total Cholesterol (TC) of pre-test and post-test of experimental group was $154.981 \pm 10.414$ and $155.006 \pm 10.416$ respectively. However, the Mean and Standard Deviation values of Total Cholesterol (TC) of pre-test and post-test of control group were $155.862 \pm 11.555$ and $155.875 \pm 11.577$. The t-value in case of experimental group was 1.000 and for control group it was 0.488 .

No significant between-group differences were noted in Total Cholesterol (TC) since the calculated value of $(\mathrm{t}=1.000)$ is smaller than tabulated value of $t .05(15)=2.13$ for the selected degree of freedom and level of significance. The data does suggest that the differences between pre-test and post-test of Total Cholesterol (TC) in experimental and control group are insignificant.
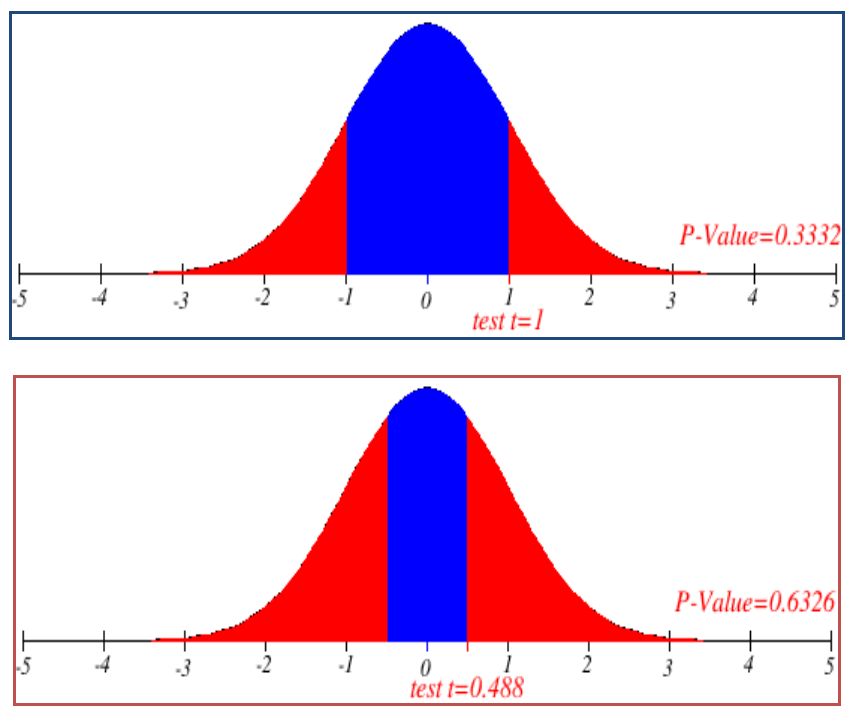

Figure 6. $t$-test and p-value for the Experimental (Pre-Test \& Post-Test) and Control (Pre-Test \& Post-Test) Groups on the parameter Total Cholesterol (TC).

\subsection{Low Density Lipoprotein Cholesterol (LDL-Cholesterol)}

The Mean and Standard Deviation values of Low Density Lipoprotein Cholesterol (LDL-Cholesterol) of pre-test and post-test of experimental group was $114.668 \pm 6.779$ and $114.687 \pm 6.769$ respectively. However, the Mean and Standard Deviation values of Low Density Lipoprotein Cholesterol (LDL-Cholesterol) of pre-test and post-test of control group were $113.081 \pm 6.266$ and $113.087 \pm 6.327$. The t-value in case of experimental group was 0.764 and for control group it was 0.222 .

No significant between-group differences were noted in Low Density Lipoprotein Cholesterol (LDL-Cholesterol) since the calculated value of $(\mathrm{t}=0.764)$ is smaller than tabulated value of $t .05(15)=2.13$ for the selected degree of freedom and level of significance. The data does suggest that the differences between pre-test and post-test of in Low Density Lipoprotein Cholesterol (LDL-Cholesterol) in experimental and control group are insignificant.
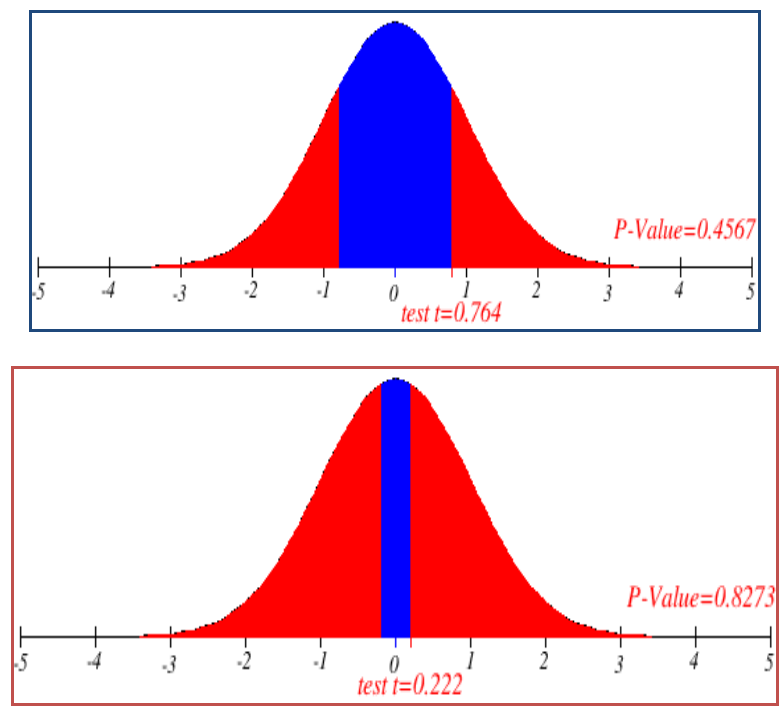

Figure 7. $t$-test and p-value for the Experimental (Pre-Test \& Post-Test) and Control (Pre-Test \& Post-Test) Groups on the parameter Low Density Lipoprotein Cholesterol (LDL-Cholesterol).

\subsection{High Density Lipoprotein Cholesterol (HDL-Cholesterol)}
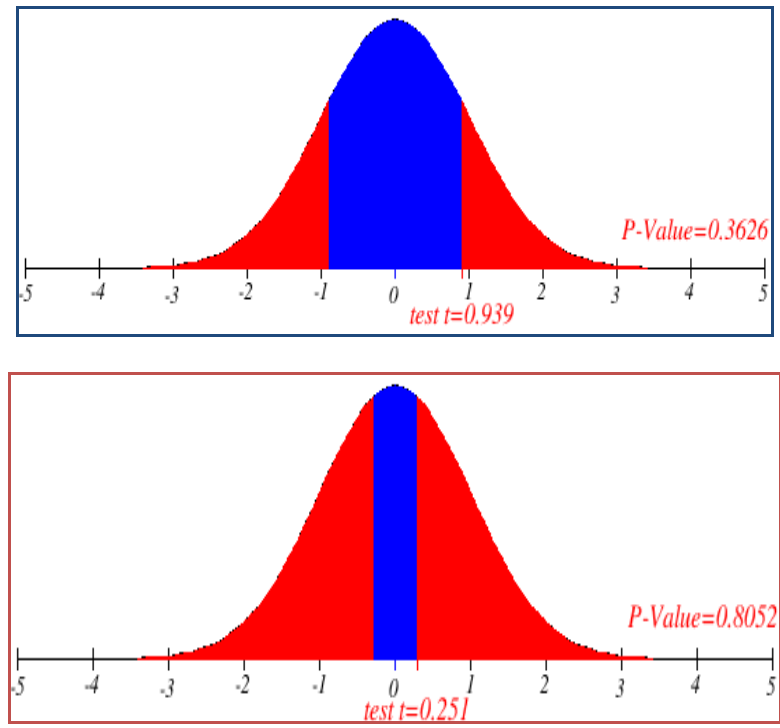

Figure 8. $t$-test and p-value for the Experimental (Pre-Test \& Post-Test) and Control (Pre-Test \& Post-Test) Groups on the parameter High Density Lipoprotein Cholesterol (HDL-Cholesterol).

The Mean and Standard Deviation values of High Density Lipoprotein Cholesterol (HDL-Cholesterol) of pre-test and post-test of experimental group was $67.850 \pm 3.559$ and $67.875 \pm 3.602$ respectively. However, the Mean and Standard Deviation values of High Density Lipoprotein Cholesterol (HDL-Cholesterol) of pre-test and post-test of control group were $70.531 \pm 5.389$ and $70.537 \pm 5.392$. The t-value in case of experimental group was 0.939 and for control group it was 0.251 .

No significant between-group differences were noted in High Density Lipoprotein Cholesterol (HDL-Cholesterol) since the calculated value of $(\mathrm{t}=939)$ is smaller than tabulated value of $t .05(15)=2.13$ for the selected degree of freedom 
and level of significance. The data does suggest that the differences between pre-test and post-test of High Density Lipoprotein Cholesterol (HDL-Cholesterol) in experimental and control group are insignificant.

\subsection{Triglycerides (TG)}

The Mean and Standard Deviation values of Triglycerides (TG) of pre-test and post-test of experimental group was $135.331 \pm 7.651$ and $135.381 \pm 7.649$ respectively. However, the Mean and Standard Deviation values of Triglycerides (TG) of pre-test and post-test of control group were 130.900 \pm 6.816 and $130.925 \pm 6.852$. The t-value in case of experimental group was 2.070 and for control group it was 1.074

No significant between-group differences were noted in Triglycerides (TG) since the calculated value of $(\mathrm{t}=2.070)$ is smaller than tabulated value of $t .05(15)=2.13$ for the selected degree of freedom and level of significance. The data does suggest that the differences between pre-test and post-test of Triglycerides (TG) in experimental and control group are insignificant.
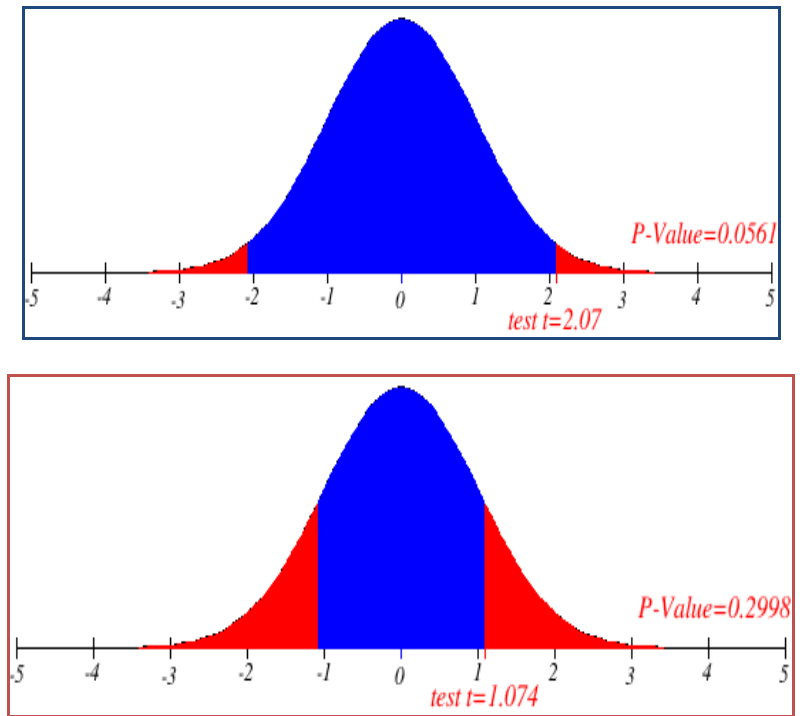

Figure 9. t-test and p-value for the Experimental (Pre-Test \& Post-Test) and Control (Pre-Test \& Post-Test) Groups on the parameter Triglycerides (TG).

\section{Conclusions}

This paper seeks to explore the effects of Bhastrika pranayama on hematological parameters of university level girls. No significant differences were found in Hemoglobin (Hb), Total Cholesterol (TC), Low Density Lipoprotein Cholesterol (LDL-Cholesterol), High Density Lipoprotein Cholesterol (HDL-Cholesterol) and Triglycerides (TG) of University Level Girls.

\section{References}

[1] Joshi, L.N., Joshi, V.D., \& Gokhale, L.V. (1992). Effect of short term Pranayama on Ventilatory functions of lung. Indian J Physiol Pharmacol. 36, 105-8.

[2] Bhattacharya, S., Pandey, U.S., \& Verma, N.S. (2002). Improvement in oxidative status with yogic breathing in young healthy males. Indian J Physiol Pharmacol. 46, 349-54.

[3] Subbalakshmi N.K., Saxena S.K., Urmimala, D., Urban J.A. (2005). Immediate effect of Nadi-shodhan Pranayama on some selected parameters of cardiovascular, pulmonary and higher functions of brain. Thai J Physiological Sciences. 18:10-16.

[4] Cooper S., Oborne J., Newton S., Harrison V., Thompson C.J., Lewis S., Tattersfield A. (2003). Effect of two breathing exercises (Buteyko and pranayama) in asthma: a randomised controlled trial. Thorax. 64-75.

[5] Dhungel K.U., Malhotra V., Sarkar D., Prajapati R. (2008). Effect of alternate nostril breathing exercise on cardiorespiratory functions. Nepal Med Coll J. 10:25-27.

[6] Ravindra P.N., Madanmohan P.P. (2006). Effect of pranayam (yogic breathing) and shavasan (relaxation training) on the frequency of benign ventricular ectopics in two patients with palpitations. Int J Cardiol. 108: 124-125, 2006.

[7] Bharshankar J.R., Bharshanker R.N., Deshpande V.N., Kaore S.B., Gosavi G.B. (2003). Effect of yoga on cardiovascular system in subjects above 40 years. Indian J Physiol Pharmacol 47 (2):202-06.

[8] Khanam A.A., Sachdev V., Guleria R., Deepak K.K. (1996). Study of pulmonary and autonomic functions of asthma patients after yoga training. Indian $\mathrm{J}$ Physiol Pharmacol. 40(4):318-24.

[9] Katiyar S.K., Bihari S. (2006). Role of pranayama in rehabilitation of COPD patients - a randomized controlled study. Indian J Allergy Asthma Immunol. 20(2):98-104.

[10] Jastrzębska M., Foltyńska A., Torbus-Lisiecka B., Chelstowski K., Pieczul-Mróz J. (2002). Klimek K. Fibrinogen and von Willebrand factor levels in relation to lipid profile and blood pressure in children whose fathers have a history of premature myocardial infraction. Polish Heart Journal. 56(6):488-95. 